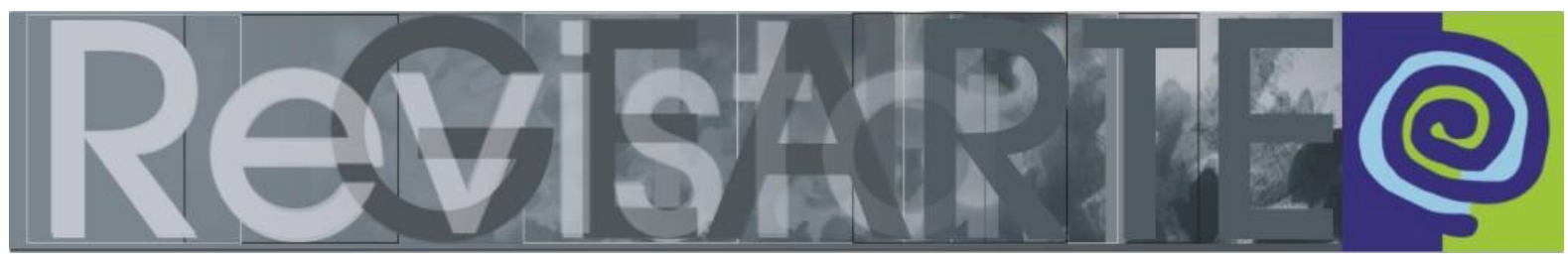

e-ISSN 2357-9854

Ensaio Visual

\title{
Quem influencia quem?
}

Ana Amália Tavares Bastos Barbosa (Universidade Estadual

Paulista Júlio de Mesquita — UNESP, São Paulo/SP, Brasil)

Moacir José da Rocha Simplicio (Moa Simplicio)

(Faculdades Metropolitanas Unidas - FMU, São Paulo/SP, Brasil)

RESUMO - Quem influencia quem? - Este ensaio é um exemplo de como utilizamos a Abordagem Triangular na aula de arte. O título se refere a se é o artista que influencia o educador ou vice-versa. PALAVRAS-CHAVE

Abordagem Triangular. Mondrian. Arte Visual.

ABSTRACT - Who influences who? - This is about Triangular Aproach and how it is used in arts class. The title deals with the doubt if it is the artist who influences the educator or viceversa.

\section{KEYWORDS}

Triangular Aproach. Mondrian. Visual Art.

SEMPRE ACHEI QUE MEU TRABALHO COMO ARTISTA ALIMENTAVA MEU TRABALHO COMO EDUCADORA E VICE-VERSA. DEPOIS DE VISITAR A EXPOSIÇÃO DE MONDRIAN COM MEU AMIGO NETO ME DEU VONTADE DE PINTAR
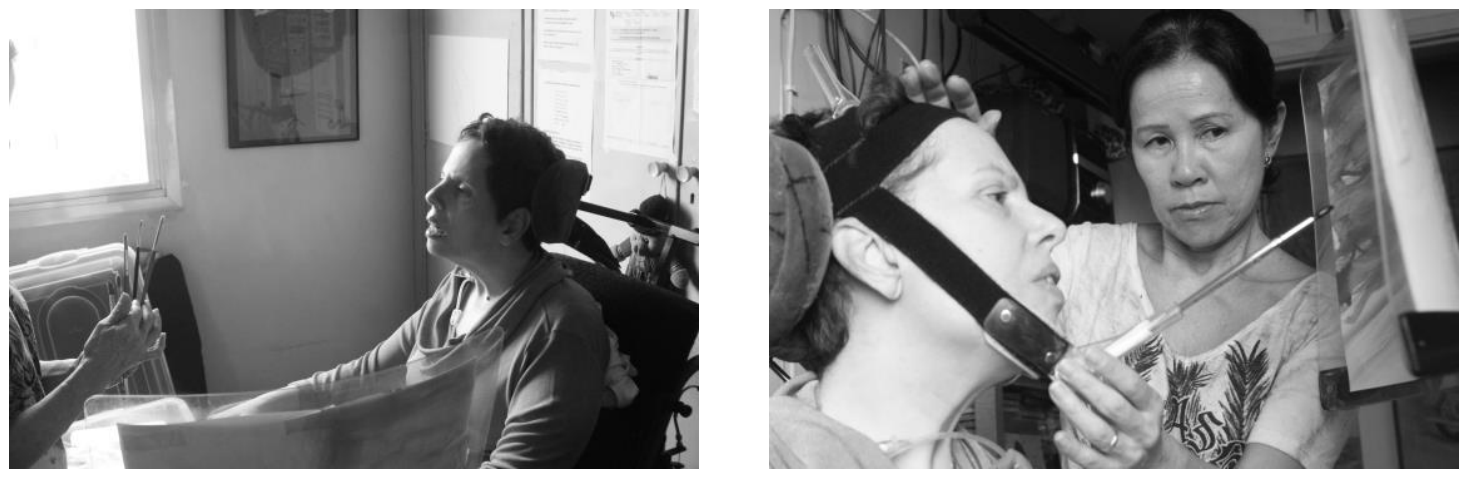

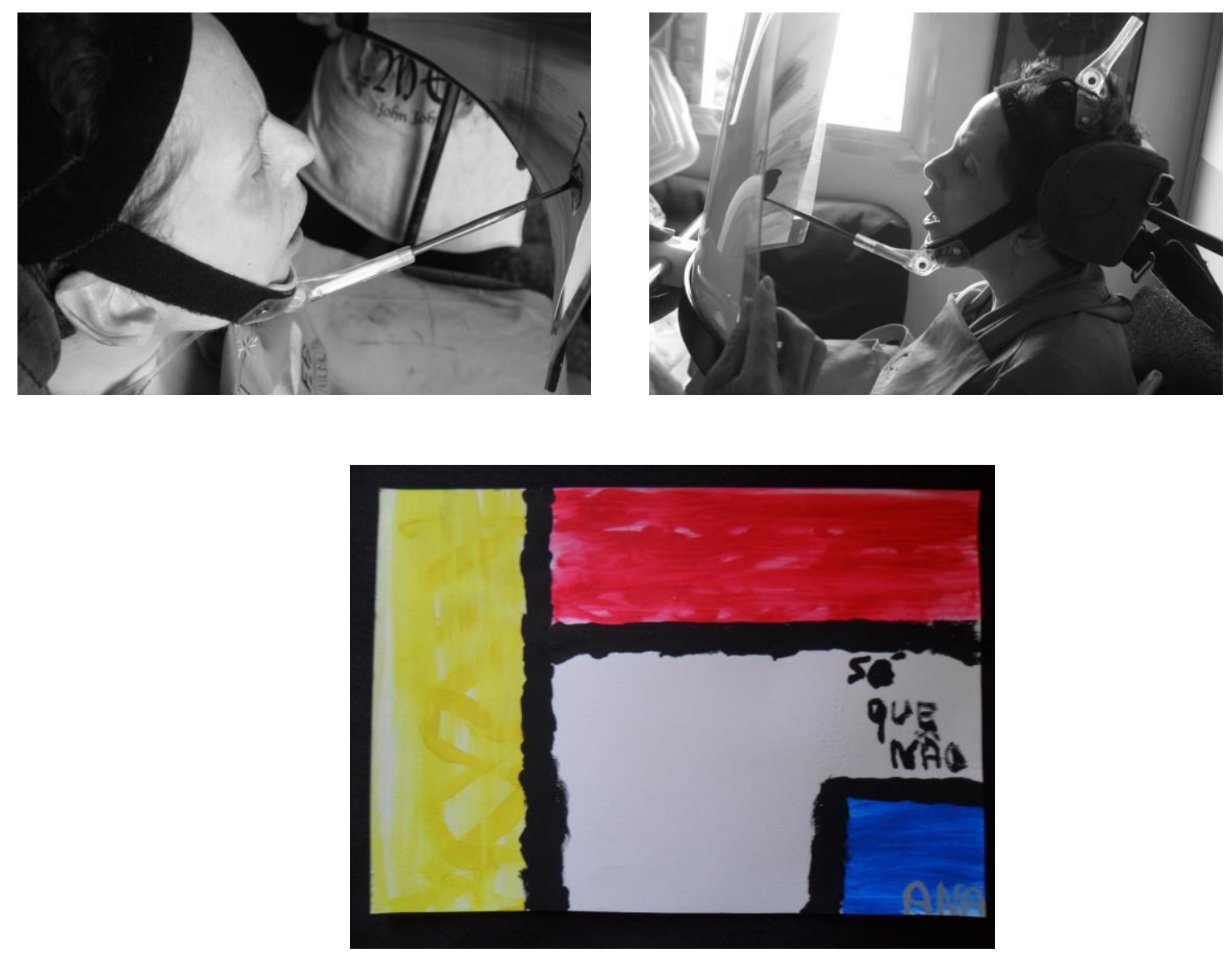

EU ESTAVA VENDO ABSTRAÇÃO COM MEUS ALUNOS ENTÃO RESOLVI FALAR DE MONDRIAN E COM A AJUDA DO MEU AMIGO MOA FIZ UM POWERPOINT SOBRE MONDRIAN

Mondrian, também, da mão direita

andava desgostado;

não por ser ela sábia:

porque, sendo sábia, era fácil.

Assim, não a trocou de braço:

queria-a mais honesta

e por isso enxertou

outras mais sábias dentro dela.

Fez-se enxertar réguas, esquadros

e outros utensílios

para obrigar a mão

a abandonar todo improviso.

Assim foi que ele, à mão direita,

impôs tal disciplina:

fazer o que sabia

como se 0 aprendesse ainda.

O SIM CONTRA O SIM - JOÃO CABRAL DE MELO NETO 

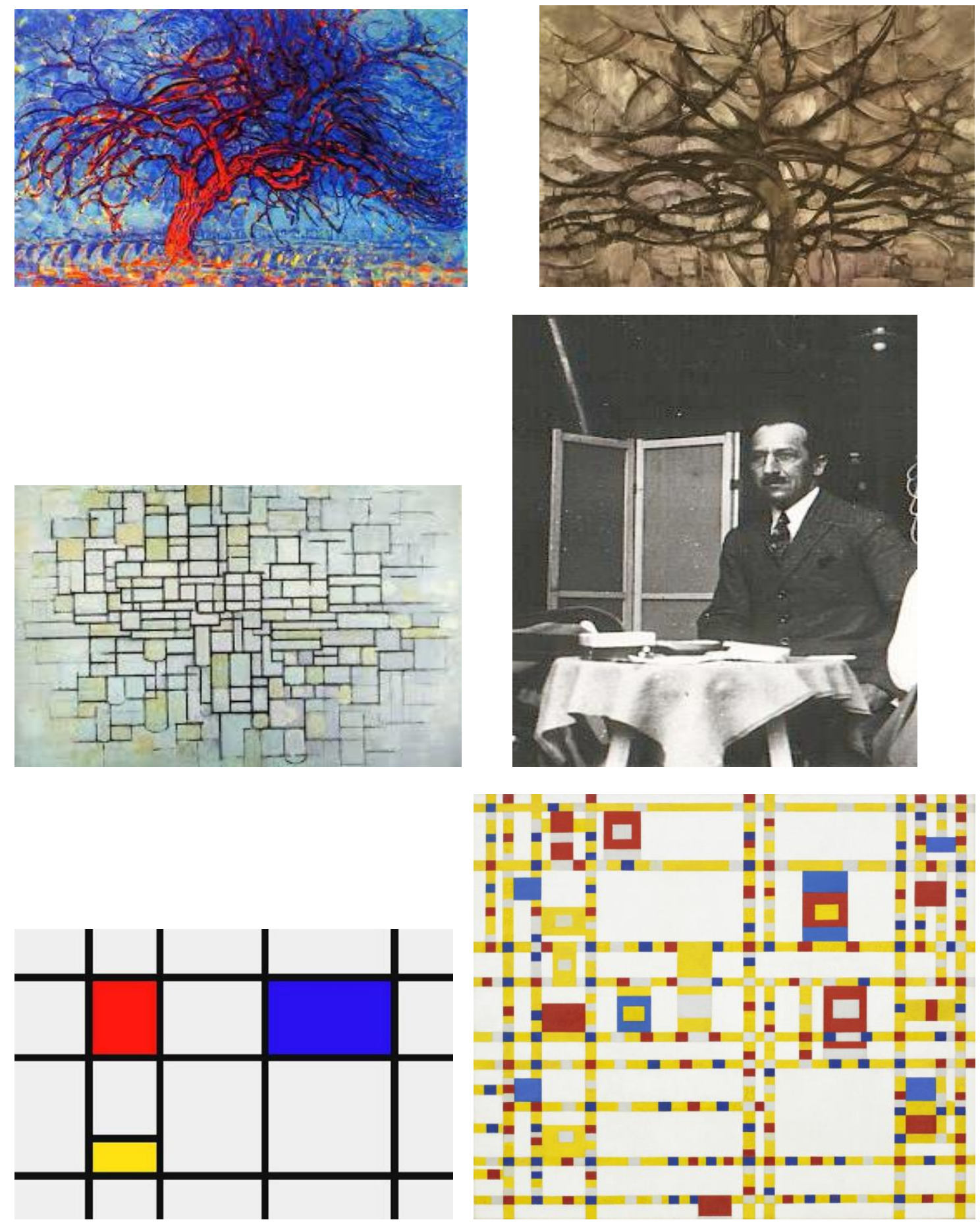

E COM A AJUDA DE VARIOS AMIGOS, ORGANIZEI UMA VISITA À EXPOSIÇÃO 

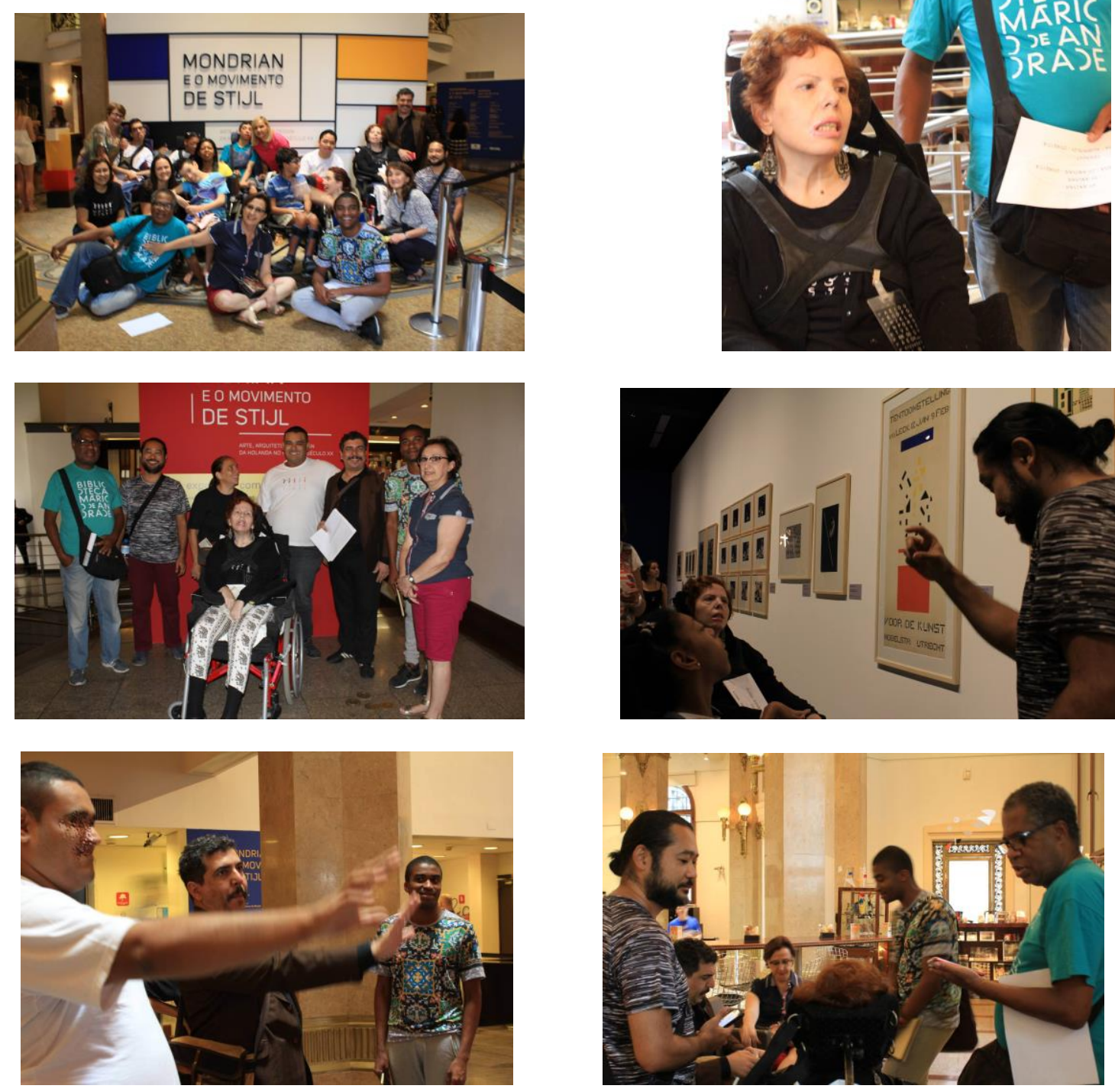

NA AULA SEGUINTE PEDI À PROFESSORA FABIANA QUE RECORTASSE QUADRADOS E RETÂNGULOS NAS CORES PRIMARIAS E FINAS FAIXAS PRETAS E PROPUS A ELES QUE, COM ESSE MATERIAL E PENSANDO NO QUE VIRAM, FIZESSEM UMA 

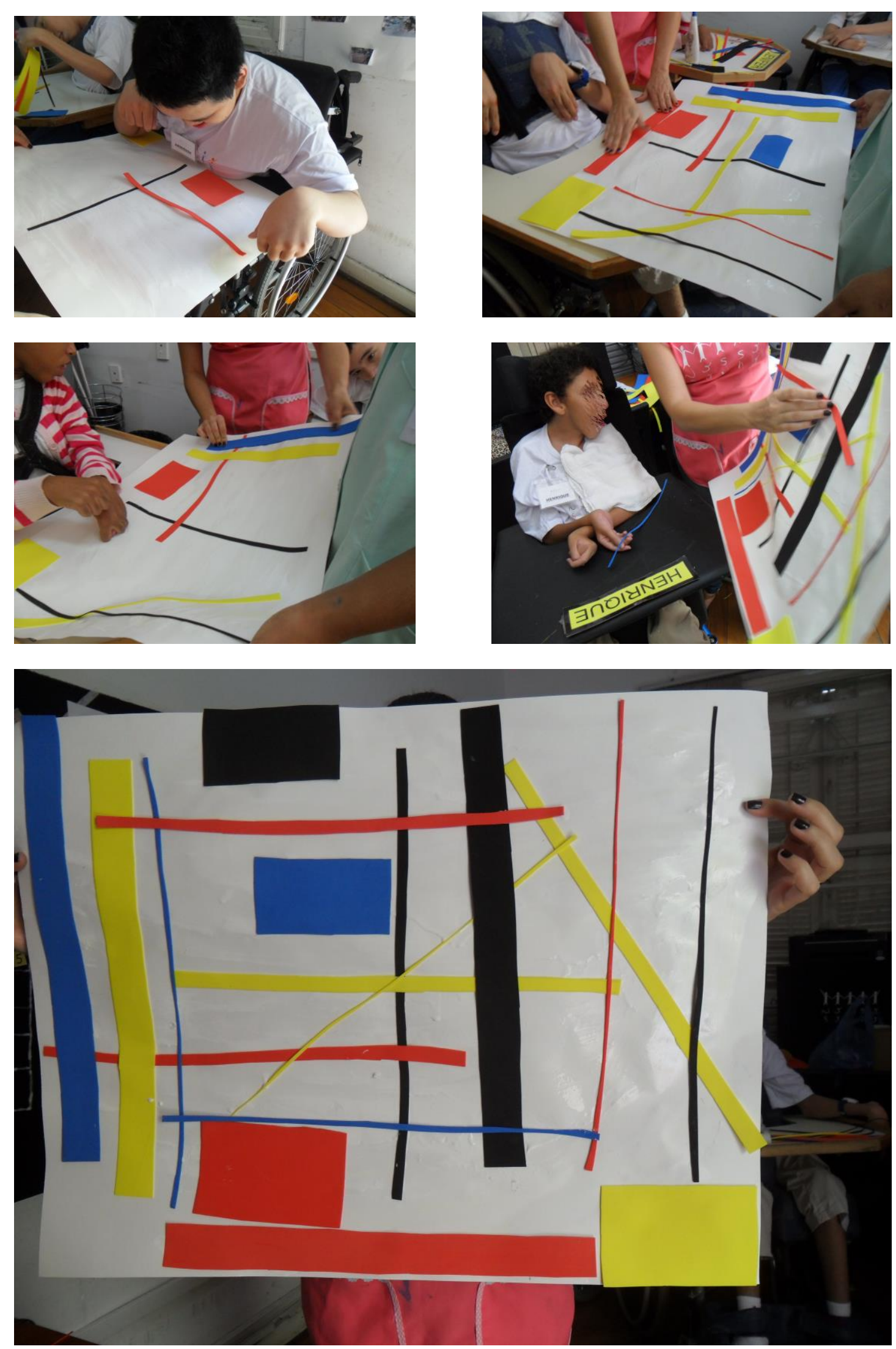


\section{Ana Amália Tavares Bastos Barbosa}

Artista plástica e arte/educadora formada pela Fundação Armando Álvares Penteado (FAAP/SP), em 1991. Estudou História da Arte na Texas University at Austin, Design na School of Visual Arts e Litografia na Columbia University em Nova lorque/EUA. Fez diversos cursos extracurriculares no Brasil com professores como Paulo Portella, Carmela Gross, Evandro Carlos Jardim, Carlos Fajardo, Paulo Von Poser e Carlos Basualdo, entre outros. Fundou a empresa "Arteducação Produções", sendo parte da equipe desde 2001. Atuou na área de ensino de línguas como professora e tradutora de inglês. É mestre e doutora pela Escola de Comunicações e Artes da USP. Defendeu a tese "Além do corpo: uma experiência em arte/educação" em maio de 2012. Atualmente desenvolve sua pesquisa de pósdoutorado da UNESP/SP sob orientação da Dra. Rosangella Leote. Em 2 de julho de 2002 teve um acidente vascular cerebral de tronco e como sequela adquiriu a Síndrome de Locked-in, ou seja, ficou tetraplégica, muda e disfágica mas inteiramente consciente e com a cognição plenamente preservada.

E-mail: aatbbl@gmail.com

Currículo: http://lattes.cnpq.br/9140964099490664

\section{Moacir Jose da Rocha Simplicio}

Mestre em Artes pela Universidade de São Paulo (USP). Ao lado do trabalho pessoal em gravura e pintura também desenvolve atividades didáticas em artes. Atualmente é professor no curso de Artes Visuais nas Faculdades Metropolitanas Unidas (FMU). Como Consultor, atuou no Minc/Ministério da Cultura (para a Segunda Conferência Nacional de Cultura). Além da consultoria, integrou o grupo de organização da Teia Paulista de Pontos de Cultura (2010), onde realizou, também, o cenário eletrônico. Coordenou o setor educativo do IMS/Instituto Moreira Salles, o curso de pedagogia da Faculdade Chafic e a implantação do projeto Mais Cultura nas Escolas pelo Ministério da Cultura. Foi Professor da PUC - Pontifícia Universidade Católica de Minas Gerais/Poços de Caldas na Faculdade de Arquitetura e Urbanismo; Professor da oficina de artes visuais para deficientes ou com mobilidade reduzida no Centro de Reabilitação UNIBAN, e professor de gravura do curso de Licenciatura da Faculdade Associada Cotia - FAAC/UNIRADIAL/Estácio e na Universidade Cruzeiro do Sul. Atuou como assistente de produção e consultoria para atendimento a pessoas com deficiência ou mobilidade reduzida da empresa AEP - Arteducação Produções com o Centro Cultural Banco do Brasil. Além de consultorias educativas, atuou em inúmeros projetos educativos por esta empresa, destacando-se alguns como: Manoel de Barros (SESC - SP), Manifestações da Fé (SESC - SP), Bienal Naif (SESC Piracicaba), entre outros. Lecionou nas Oficinas Oswald de Andrade, Maria Antônia (USP) e Associação Cultural Cachuera! Orientou o curso de papel artesanal e gravura no Atelier Experimental de Gravura Francesc Domingo do MAC/USP - Museu de Arte Contemporânea da Universidade de São Paulo; foi Assistente de professores no Departamento de Artes Plásticas da ECA/USP - Escola de Comunicações e Artes da Universidade de São Paulo. Participou como fotógrafo nos projetos Foto na Praça e no projeto Acervo das Tradições. Entre outras exposições, participou da Mostra Internacional de Mini Gravats, em Barcelona; Projeto Novas Imagens (Meridiano-Meridian) Milão - Itália; expôs gravuras no Café do MAC-USP da Cidade Universitária; no Projeto Gravura Paulista - Primeira Revisão da Gravura, na Universidade de Brasília; e no Museu da Gravura da cidade de Curitiba. Ilustrou os livros Espumas Flutuantes, de Castro Alves, Lembranças de Esquecer, de Camilo Guimarães e Cidadela Ardente, de Thelma Guedes, pela editora Ateliê Editorial.

E-mail: moasimplicio@gmail.com

Currículo: http://lattes.cnpq.br/8210204276290122

Recebido em 24 de maio de 2017 Aceito em 29 de junho de 2017 